\title{
Perception regarding reproductive health among adolescents of rural Sindh, Pakistan
}

\author{
Anjum Shahid', Abdul Ghaffar Pirzada', Ashfaque Ahmed Memon
}

${ }^{1}$ Principal Research Officer, ${ }^{2}$ Medical Officer, ${ }^{3}$ Statistical Officer, Pakistan Medical Research Council, Research Centre, National Institute of Child Health, Karachi, Pakistan.

\begin{abstract}
Adolescence, the second decade of life, is a period in which an individual undergoes major physical and psychological changes. Adolescence is a period when health problems that have serious immediate consequences can occur or when problem behaviours that could have serious adverse effects on health in the future are initiated. This study examines the knowledge and perception regarding reproductive health and opinion toward reproductive health education among adolescents of rural Sindh, Pakistan. Study was conducted in 2008- 2009 on a total number of 369 adolescent males (209) and females (160) studying in colleges of Kambar Shadadkot, rural Sindh. This descriptive study using cluster sampling technique was conducted in randomly selected eight intermediate colleges of boys and girls. After informed consent and ensuring confidentiality, an anonymous quantitative questionnaire was completed to ascertain the knowledge of adolescents. Main outcome measures were adolescent's knowledge of reproductive health concepts, pregnancy and contraceptive methods and knowledge in relation to sexually transmitted diseases (STDs) and HIV/AIDS. Analysis of data revealed that a sizable proportion of adolescents had low knowledge regarding reproductive health issues and had misconception regarding reproductive physiology, STDs and condoms. Teacher was the focal source of information and $63 \%$ male and $43 \%$ female respondents desired a need for RH education. More than half of participants had no knowledge on STDs and HIV/AIDS and its spread and a small percentage had awareness regarding contraceptive methods, about condom use and its protective coverage against STD's and pregnancy. Strong efforts are needed to augment awareness among rural adolescents and education could serve the purpose. Gender-based ethnically amenable sex education curriculum should be introduced in educational institutions.
\end{abstract}

Keywords: Adolescence, Knowledge, Reproductive, Sexual health, Pakistan.

\section{Introduction}

Adolescence is defined as a period of transition from childhood to adulthood and comprises the individuals between the ages of 10-19 years. ${ }^{1}$ Adolescents comprise $20 \%$ of the world's total population and out of 1.2 billion adolescents worldwide, nearly $90 \%$ live in developing countries. ${ }^{2,3}$ The census of Pakistan quotes the current generation of 10-19 years old at 46.5 millions constituting $30 \%$ of total, probably largest in the history of Pakistan. The boys constitute $52 \%$ of adolescent population as compared to $48 \%$ girls.

Adolescent reproductive health $(\mathrm{RH})$ is one of the most susceptible health issues that the world has been facing. The reproductive and sexual health needs of adolescents are different from those of adults and are still poorly understood in most of the world. It is also true that the RH needs and sexual behavior of adolescents vary with sex, marital status, class, region and cultural context. ${ }^{5}$ Globally, reproductive capability is taking place at an earlier age than in the past ${ }^{7}$ and adolescents are indulging in risk taking behaviors. ${ }^{6}$ Adolescence, the second decade of life, is a period in which an individual undergoes major physical and psychological changes. In adolescence, health problems that have serious immediate consequences can

\section{Practice points}

- Adolescence, the second decade of life, is a period in which an individual undergoes major physical and psychological changes.

- In adolescence, health problems that have serious immediate consequences can occur or serious adverse effects on health in the future are initiated.

- The present study demonstrated rural adolescents had low knowledge, attitude and misconceptions regarding reproductive health issues, especially STDs and HIV/AIDS.

- The findings of the present study emphasize to enhance adolescents' awareness and autonomy to enable informed decision-making to protect and improve their health and well-being, including sexual and reproductive health.

- There is an urgent need to promote adolescent sexual and reproductive health which will have far-reaching impacts and implications for young people, communities and nations.

Correspondence: Dr Anjum Shahid. PMRC, Research Centre on Child Health, $5^{\text {th }}$ Floor, National Institute of Child Health, Karachi, Pakistan.E-mail:pmrc_srcch@yahoo.com. 
occur or when problem behaviours that could have serious adverse effects on health in the future are initiated. ${ }^{7}$ Data shows that age at marriage for both young men and women is rising in almost all the countries of the world and there is an increased likelihood of premarital sexual activity, that is unsafe. ${ }^{9,10}$ Unintended pregnancy, maternal mortality, risk of induced abortions under unsafe conditions and contracting sexually transmitted diseases including HIV/AIDS are much higher among this segment than others. ${ }^{11}$ In the United States, teen pregnancy, birth, abortion and sexually transmitted disease rates are higher than those in most other developed countries and are rising. ${ }^{12}$ Surveys are being conducted around the globe in adolescents to ascertain their knowledge on RH issues and a recent survey of Malaysia reported lack of knowledge regarding important aspects of sexual and $\mathrm{RH}$ and warrants the need to strengthen sexual and $\mathrm{RH}$ education. ${ }^{13}$ While an earlier study from Pakistan reported gaps in knowledge about sexual health and misconceptions associated with them. ${ }^{14}$ Rural areas are considered to have a more restrictive socio-cultural environment regarding issues related to reproduction and sexuality. ${ }^{15}$ This study was therefore an attempt to explore the knowledge and perceptions regarding $\mathrm{RH}$ and opinion toward $\mathrm{RH}$ education among adolescents of a rural district of Sindh, Kambar Shadadkot. It includes both male and female teenagers to get a gender perspective on the subject.

\section{Materials and Methods}

A cross-sectional descriptive study using cluster sampling technique was conducted in 2008-2009 in randomly selected eight intermediate colleges of boys and girls from a rural district of Sindh, Kambar Shadadkot. The sample size of 369 was calculated at $95 \%$ confidence interval with $5 \%$ precision and expected prevalence of $40 \%$ using computer package EPI info 6 version $6 .^{16} \mathrm{~A}$ total number of 369 adolescent (17-19 years) college boys (209) and girls (160) were included in the study. After informed consent and ensuring confidentiality, an anonymous questionnaire, designed at the research centre was filled by trained researchers and all respondents were interviewed individually to ascertain their knowledge regarding contraceptive methods, STD'S and AIDS and their opinion towards RH education. Pilot tests were conducted in two colleges which were not selected for survey.

Ethical clearance was obtained from the Ethical Review Committee of the Institute and informed written consent was taken from the respondents before interview. Assurance of confidentiality was provided to the participants.

Data feeding and analysis was accomplished by using computer SPSS (Statistical Package for Social Sciences) Version 11.0. The results were given as frequency/ percentage for qualitative variables. A p-value below 0.05 was considered as statistically significant.

\section{Results}

This study was conducted in 369 adolescents (17-19 years), comprising of 209 males and 160 females of 8 public sector colleges of Kambar Shadadkot, Sindh. Mean age of cohort was $18.34 \pm 0.57$ years while that of male and female respondents was $18.26 \pm 0.54$ years and $18.44 \pm 0.6$ years respectively. General characteristics of adolescents are presented in Figure 1. More than 70\% (117) girls were from pre-medical group while $40 \%$ (84) boys were from preengineering group.

Figure1: General characteristics of adolescents

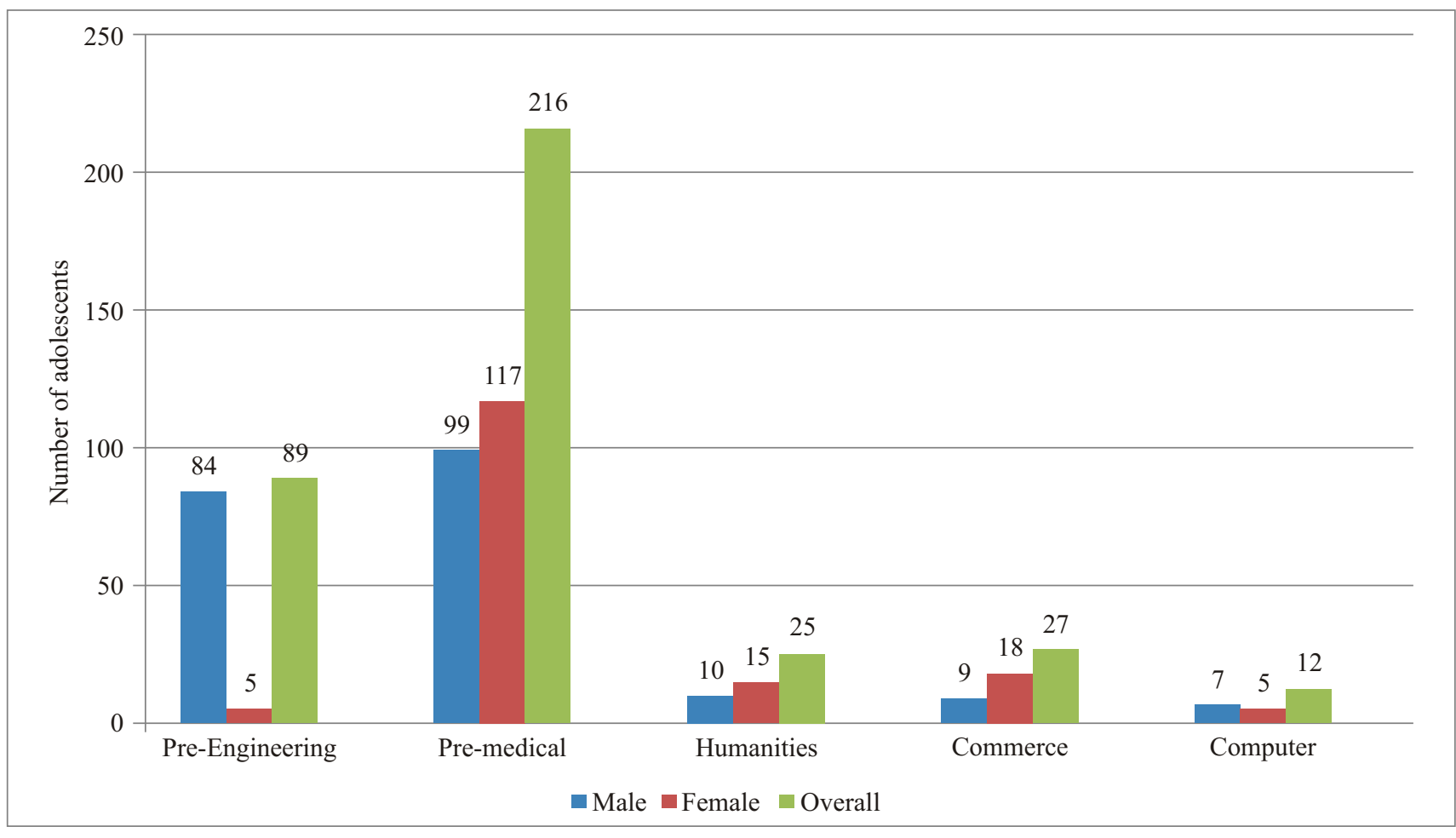

South East Asia Journal of Public Health 2012;2(1):39-45. 
Table 1: Communication with elders

\begin{tabular}{|c|c|c|c|c|}
\hline \multirow[t]{2}{*}{ Variables } & \multicolumn{3}{|c|}{ Adolescents (\%) } & \multirow[t]{2}{*}{ p-value } \\
\hline & Overall $(\mathrm{n}=369)$ & Male $(\mathrm{n}=209)$ & Female $(n=160)$ & \\
\hline \multicolumn{5}{|c|}{ Relationship With elders } \\
\hline Respectful & $310(84.01 \%)$ & $170(81.34 \%)$ & $140(87.50 \%)$ & 0.11 \\
\hline Friendly & $49(13.28 \%)$ & $31(14.83 \%)$ & $18(11.25 \%)$ & 0.31 \\
\hline Afraid & $7(1.90 \%)$ & $5(2.40 \%)$ & $2(1.25 \%)$ & 0.09 \\
\hline Shy & $2(0.54 \%)$ & $2(0.96 \%)$ & 0 & - \\
\hline Uncaring & $1(0.27 \%)$ & $1(0.48 \%)$ & 0 & - \\
\hline \multicolumn{5}{|c|}{ How do you feel when communicating with elders about RH? } \\
\hline Shyness & $151(40.92 \%)$ & $91(43.54 \%)$ & $60(37.50 \%)$ & 0.24 \\
\hline Bold/outspoken & $41(11.11 \%)$ & $30(14.35 \%)$ & $11(6.9 \%)$ & $0.02 *$ \\
\hline Cannot talk & $78(21.14 \%)$ & $64(30.62 \%)$ & $14(8.75 \%)$ & $0.001^{*}$ \\
\hline Others & $7(1.9 \%)$ & $2(0.96 \%)$ & $5(3.12 \%)$ & $0.03 *$ \\
\hline Don't Know & $92(24.93 \%)$ & $22(10.53 \%)$ & $70(43.75 \%)$ & $0.001^{*}$ \\
\hline \multicolumn{5}{|c|}{ Does your family allow you to make girls/boy friends? } \\
\hline Yes & $65(17.62 \%)$ & $26(12.44 \%)$ & $39(24.37 \%)$ & \multirow[t]{2}{*}{$0.001^{*}$} \\
\hline No & $186(50.41 \%)$ & $153(73.21 \%)$ & $33(20.63 \%)$ & \\
\hline Don't know & $118(31.98 \%)$ & $30(14.35 \%)$ & $88(55 \%)$ & $0.001 *$ \\
\hline
\end{tabular}

*Values are significant $p<0.05$.

\section{Communication with elders}

About $84 \%$ of students were of the opinion that their behavior was respectable with elders and $40 \%$ feel shy while communicating with elders regarding $\mathrm{RH}$ issues (Table 1). More girls (24\%) than boys (12\%) were allowed by family to converse with members of opposite gender and the difference was highly significant $(p=0.001)$.

\section{Reproductive health education/information}

The teacher was the foremost source of $\mathrm{RH}$ information to adolescent boys (58\%) and girls (36\%) and they believed in improving awareness for the same (Table 2). According to $46 \%,<18$ yrs was the right age for imparting $\mathrm{RH}$ education. More females than males made no rejoinder and this difference was highly significant $(\mathrm{p}=0.001)$. About $63 \%$ of male and $43 \%$ of female respondents emphasized a need for $\mathrm{RH}$ education and $55 \%$ of the respondents identified negative attitude of the society as the main barrier of acquiring such knowledge. Difference in opinion between the genders was highly significant $(\mathrm{p}=0.001)$.

\section{Awareness of STD's, AIDS and Contraceptive methods}

More than half of respondents had no knowledge on STD's and HIV/AIDS and its spread, and about $25 \%$ were of the opinion that AIDS can be cured (Table 3). About $40 \%$ females made no rejoinder and difference in gender opinion was significant (0.001). Although $12 \%$ were aware of contraceptive methods but only $9 \%$ had knowledge about condom use and more boys (13\%) than girls (3\%) knew about condoms. That condoms are protective against STI's been recognized by $16 \%$ and $12 \%$ knew that they are effective against preventing pregnancy.

\section{Premaritalsex}

Regarding premarital sex, boys (47\%) had a more liberal opinion than girls $(21 \%)$ and about $68 \%$ of females and $19 \%$ of males made no rejoinder on this subject which was highly significant $(\mathrm{p}=0.001)$.

\section{Discussion}

The present study presents the status of rural adolescent's knowledge and perception about RH. Data on rural adolescent $\mathrm{RH}$ is scarce in Pakistan as taboos surrounding discussion of sexuality is a key constraint in Pakistani culture and as a result little is known about the RH needs of young people. The rural environment is a unique and potentially challenging socio-cultural context for adolescent health and more restrictive regarding issues related to reproduction and sexuality.

Adolescents in the contemporary study do not have access to sufficient and correct information of RH issues. This lack 
Table 2: Reproductive health education

\begin{tabular}{|c|c|c|c|c|}
\hline \multirow[t]{2}{*}{ Variables } & \multicolumn{3}{|c|}{ Adolescents (\%) } & \multirow[t]{2}{*}{ p-valuc } \\
\hline & Overall $(n=369)$ & Male $(\mathrm{n}=209)$ & Female $(\mathrm{n}=160)$ & \\
\hline Books & $95(25.74 \%)$ & $50(23.92 \%)$ & $45(28.12 \%)$ & 0.36 \\
\hline Media /internet & $27(7.32 \%)$ & $8(03.83 \%)$ & $19(11.88 \%)$ & $0.003^{*}$ \\
\hline Teacher & $179(48.51 \%)$ & $121(57.89 \%)$ & $58(36.25 \%)$ & $0.001^{*}$ \\
\hline Parents & $38(10.3 \%)$ & $20(9.57 \%)$ & $18(11.25 \%)$ & 0.596 \\
\hline Friends & $19(5.05 \%)$ & $8(3.83 \%)$ & $11(6.88 \%)$ & 0.189 \\
\hline Others & $11(2.89 \%)$ & $2(0.96 \%)$ & $9(5.62 \%)$ & $0.009^{*}$ \\
\hline \multicolumn{5}{|c|}{ In your opinion what is the right age for RH education? } \\
\hline$<18$ Years & $171(46.34 \%)$ & $126(60.29 \%)$ & $45(28.13 \%)$ & 0.259 \\
\hline$>18$ Years & $30(8.13 \%)$ & $25(11.96 \%)$ & $5(3.12 \%)$ & \\
\hline Don’t know & $168(45.53 \%)$ & $58(27.75 \%)$ & $110(68.75 \%)$ & $0.001 *$ \\
\hline \multicolumn{5}{|c|}{ Is there any need for RH education? } \\
\hline Yes & $201(54.47 \%)$ & $132(63.16 \%)$ & $69(43.12 \%)$ & 0.887 \\
\hline No & $98(26.56 \%)$ & $65(31.1 \%)$ & $33(20.6 \%)$ & \\
\hline Don’t Know & 7018.97 & $12(5.74 \%)$ & $58(36.25 \%)$ & $0.001^{*}$ \\
\hline \multicolumn{5}{|c|}{ Barrier for RH education, whose negative attitude? } \\
\hline Parents & $83(22.49 \%)$ & $25(11.96 \%)$ & $58(36.25 \%)$ & $0.001 *$ \\
\hline Teacher & $81(21.95 \%)$ & $35(16.75 \%)$ & $46(28.75 \%)$ & $0.005^{*}$ \\
\hline Society & $205(55.56 \%)$ & $149(71.29 \%)$ & $56(35 \%)$ & $0.001 *$ \\
\hline \multicolumn{5}{|c|}{ Do you believe in improving RH education? } \\
\hline Yes & $180(48.78 \%)$ & $124(59.33 \%$ & $56(35 \%)$ & $0.024 *$ \\
\hline No & $136(36.86 \%)$ & $77(36.84 \%)$ & $59(36.88 \%)$ & \\
\hline Don't Know & $53(14.36 \%)$ & $8(3.83 \%)$ & $45(28.12 \%)$ & $0.001 *$ \\
\hline
\end{tabular}

$* *$ Values are significant $p<0.05$.

of knowledge concerning reproduction can be attributed to social and cultural barriers. ${ }^{17}$ It is important to promote and protect the rights of adolescents to $\mathrm{RH}$ information and care as RH behaviors of adolescents are directly related to their own health as future adults. ${ }^{18,19}$ However, the findings of the present study do not reflect this recognition. There is a great need for RH information on the risks and prevention of pregnancy, STD's and HIV/AIDS. Reproductive health education is a key strategy for promoting safe sexual behavior among teenagers ${ }^{20}$ and acquiring knowledge about the dilemma and misconceptions. ${ }^{20}$ More than $50 \%$ of the respondents in this study were of the need for RH education the finding coincides with an earlier study conducted in adolescent males in rural Pakistan where respondents were willing to learn more of the issue. ${ }^{14}$ As per their rejoinder, society was the main barrier in acquisition of the said knowledge and considered $<18$ years as the right age for imparting RH education. A recent study demonstrated that positive well-being during adolescence predicts better perceived general health and fewer risky health behaviors during young adulthood. ${ }^{15}$ Aligned with the goals of the positive youth development perspective, promoting and nurturing positive well-being during the transition from childhood to adolescence may present a promising way to improve long-term health.

The present study demonstrated that discussion of $\mathrm{RH}$ issues with teachers were common in both male and female respondents. This shows that though strong family structure considered a major role in the lives of adolescents but a shift of trend was identified which advocated that parents are no longer their first point of contact. 
Table 3: Knowledge of STD'S, AIDS and contraceptive methods

\begin{tabular}{|c|c|c|c|c|}
\hline \multirow[t]{2}{*}{ Variables } & \multicolumn{3}{|c|}{ Adolescents (\%) } & \multirow[t]{2}{*}{ p-value } \\
\hline & Overall $(n=369)$ & Male $(n=209)$ & Female $(n=160)$ & \\
\hline \multicolumn{5}{|c|}{ Have you heard about STI's / AIDS? } \\
\hline Yes & $90(25.62 \%)$ & $49(23.44 \%)$ & $41(25.62 \%)$ & \\
\hline No & $232(62.87 \%)$ & $159(76.08 \%)$ & $73(45.63 \%)$ & 0.81 \\
\hline Don’t know & $47(12.73 \%)$ & $1(0.48 \%)$ & $46(28.75 \%)$ & $0.001^{*}$ \\
\hline \multicolumn{5}{|c|}{ How HIV/AIDS Spread? } \\
\hline Yes & $54(14.63 \%)$ & $35(16.75 \%)$ & 1911.88 & \\
\hline No & $235(63.69 \%)$ & $171(81.82 \%)$ & $64(40 \%)$ & 0.24 \\
\hline Don't know & $80(21.68 \%)$ & $3(1.43 \%)$ & $77(48.12 \%)$ & $0.001 *$ \\
\hline \multicolumn{5}{|c|}{ Is it possible to cure AIDS? } \\
\hline Yes & $90(24.4 \%)$ & $49(23.44 \%)$ & $41(25.62 \%)$ & \\
\hline No & $188(50.94 \%)$ & $136(65.07 \%)$ & $52(32.5 \%)$ & $0.003^{*}$ \\
\hline Don't know & $91(24.66 \%)$ & $24(11.48 \%)$ & $67(41.88 \%)$ & $0.001^{*}$ \\
\hline \multicolumn{5}{|c|}{ Do you have knowledge about contraceptives methods? } \\
\hline Yes & $45(12.2 \%)$ & $31(14.8 \%)$ & $14(8.75 \%)$ & \\
\hline No & $220(59.6 \%)$ & $159(76.1)$ & $61(38.12 \%)$ & 0.646 \\
\hline Don't know & $104(28.2 \%)$ & $19(09.1 \%)$ & $85(53.13 \%)$ & $0.001^{*}$ \\
\hline \multicolumn{5}{|c|}{ Do you have knowledge about condoms? } \\
\hline Yes & $33(8.94 \%)$ & $28(13.4 \%)$ & $5(3.12 \%)$ & \\
\hline No & $244(66.13 \%)$ & $161(77.03 \%)$ & $83(51.88 \%)$ & $0.028 *$ \\
\hline Don't know & $92(24.93 \%)$ & $20(9.57 \%)$ & $72(45 \%)$ & $0.001^{*}$ \\
\hline \multicolumn{5}{|c|}{ Are condoms protective against STIs? } \\
\hline Yes & $60(16.3 \%)$ & $49(23.44 \%)$ & $11(6.88 \%)$ & \\
\hline No & $210(56.9 \%)$ & $139(66.51 \%)$ & $71(44.37 \%)$ & $0.021 *$ \\
\hline Don’t Know & $99(26.8 \%)$ & $21(10.05 \%)$ & $78(48.75 \%)$ & $0.001^{*}$ \\
\hline \multicolumn{5}{|c|}{ Are condoms effective in preventing pregnancy? } \\
\hline Yes & $46(12.47 \%)$ & $26(12.44 \%)$ & $20(12.5 \%)$ & \\
\hline No & $238(64.49 \%)$ & $163(77.99 \%)$ & $75(46.87 \%)$ & 0.115 \\
\hline Don't Know & 85 (23.04\%) & $20(09.57 \%)$ & $20(40.63 \%)$ & $0.001 *$ \\
\hline
\end{tabular}

$* *$ Values are significant $p<0.05$.

Similar is the case with friends; though an earlier study reported that youths rely on each other for information on $\mathrm{RH}$ matters and resolve any RH problem within the peer system. ${ }^{14}$ Adolescents in this study had developed their own channels of informal information from a relatively diverse set of sources but knowledge gained cannot be accepted as appropriate and undoubtedly can be incorrect and inadequate. ${ }^{21}$ The present situation is similar to an earlier study conducted in Bangladesh ${ }^{22}$ but disparate to that of Iran. ${ }^{10}$
The present study also revealed that a substantial proportion of respondents had low knowledge about the STDs, HIV/AIDS and their spread, about contraceptives and its protective coverage against STDs and pregnancy. It is a matter of serious concern as more than half of respondents had no knowledge on STDs and HIV/AIDS. They had misconceptions regarding STD's and about $50 \%$ were of the view that STD's do not occur during adolescent years. Previous study conducted among the college students of 
eight cities of Sindh province (Pakistan) showed that $92 \%$ of the respondents considered AIDS were the threat to the health of Pakistan. ${ }^{23}$ This findings identified the differences of knowledge of rural and urban students which need special attention by the policy makers. A population-based study of 1,385 males aged 15-18 years in Tehran, Iran also reported that nearly all (95\%) of the respondents had heard about STIs and HIV/AIDS, but misconceptions were widespread. ${ }^{10}$ Another study conducted on adolescent girls from rural Bangladesh indicated that a sizable proportion of adolescent girls had incorrect knowledge or misconceptions about the fertile period, reproduction, sexually transmitted diseases, and HIV/AIDS. ${ }^{24}$

The findings of the present study highlighted the poor knowledge of contraceptive use and misconception regarding use of condoms. About one-tenth of the respondents was aware of contraceptives and had knowledge about condoms. Less than one-fifth of the respondents had knowledge that condoms were protective against STD's and effective against preventing pregnancy. The awareness was low in comparison to an earlier study among urban college students in Pakistan ${ }^{10}$ and another study conducted on rural adolescents in Bangladesh. ${ }^{25} \mathrm{We}$ also reported in another study ${ }^{26}$ about knowledge, attitude and behavior about reproductive and sexual health in urban adolescents of Karachi, Pakistan and found that they were better equipped than their rural counterpart studied in the present study. Reproductive health education as part of the curriculum can provide an effective means of improving knowledge and reducing RH problems among them.

The findings of the present study emphasized the urgent need to enhance adolescents' awareness and autonomy to enable informed decision-making and reduce unsafe and unwanted sexual activity, especially in rural areas. Parents, teachers and the adult community must facilitate this decision-making through free and open communication and by creating a friendly environment that protects adolescents from abuse, and enables them to access information and services without fear. ${ }^{27}$ A culturally relevant RH curricula should be introduced in the school and colleges to promote awareness regarding adolescent sexual and reproductive health. ${ }^{28}$ Finally, a shared understanding of adolescent health would have to be developed by strengthening health service provision by making it adolescent friendly. ${ }^{29}$

\section{Conclusion}

The findings of the present study demonstrated that a sizable proportion of rural adolescents had low knowledge, attitude and misconceptions regarding RH issues, especially STDs and HIV/AIDS. Policymakers should take appropriate and urgent actions to promote adolescent sexual and RH which will have far-reaching impacts and implications for young people, communities and nations.

\section{References}

1. UNICEF. The State of The World's Children 2011. New York: United Nations Children's Fund, 2011.

2. UNICEF. Progress for children: A report card on adolescents. New York: United Nations Children's Fund, 2011.

3. WHO. The second decade: Improving adolescent health and development. Geneva: World Health Organization, 2001.

4. Hanum SH. Teenage Marriage. Yogyakarta: Pusat Penelitian Kependudukan Universities Gadjah Mada, 1997.

5. WHO. Progress in reproductive health research. Geneva: World Health Organization, 2003.

6. WHO/UNFPA/UNICEF. Action for adolescent health: Towards a common agenda: Recommendations from a joint study group. Geneva: World Health Organization, 1997.

7. WHO. Strengthening the health sector response to adolescent health and development. Geneva: World Health Organization, 2009.

8. Steinberg L, Dahit R, Ann S, Daniel S. The study of developmental psychopathology in adolescence. In: Cicchetti (ed). Developmental Psychopathology. New York: John Wiley \& Sons, 2004.

9. DeJong J, Jawad R, Mortagy I, Shepard S. The sexual and reproductive health of young people in the Arab countries and Iran. Reprod Health Matters 2005;13:49.

10. Mohammadi RM, Mohammad K, Farahani FK. Reproductive knowledge, attitudes and behavior among adolescent males in Tehran, Iran. Int Fam Plann Perspect 2006;32:35-44.

11. Harrison K. Maternal mortality in Nigeria. The real issues. Afr J Rep Health 1997;1:7-13.

12. Singh S, Darroch JE. Adolescent pregnancy and child bearing: Levels and trends in developed countries. Fam Plann Perspect 2000:321:14-23.

13. Ab Rahman A, Ab Rahman R, Ibrahim MI, Saleh H, Ismail SB, Ali SH. et al. Knowledge of sexual and reproductive health among adolescents attending school in Kelantan, Malaysia. Southeast Asian J Trop Med Pub Health 2011; 42:717-25.

14. Ali M, Bhatti MA, Ushjima H. Reproductive health needs of adolescent males in rural Pakistan: an exploratory study. Tohoku J Exp Med 2004;204:17-25.

15. Hoyt LT, Chase-Lansdale PL, McDade TW, Adam EK. Positive Youth, Healthy Adults: Does Positive Wellbeing in Adolescence Predict Better Perceived Health and Fewer Risky Health Behaviors in Young Adult. J Adolesc Health 2012; 50:66-73. 
16. Cherry DC, Huggins B, Gilmore K. Children's health in the rural environment. Pediatric Clin North Am 2007;54:121-33.

17. Kilbourne-Brook, M. Adolescent reproductive health: making a difference. Outlook 1998;16:1-8.

18. Rice M: Adolescent sexual and reproductive health. Reprod Biomed Online 2000; 1:78-86.

19. WHO. Working with adolescent. Report of a workshop. Geneva: World Health Organization, 2000.

20. Lindberg ID, Ku L, Somenstein F. Adolescents' reports of reproductive health, education. 1988 and 1995. Fam Plann Perspect 2000; 32:220-6.

21. Kapamadzija A, Bjelica A, Segidi D. Sex knowledge and behavior in male high school students. Med Pregl 2000; 53:595-9.

22. Rob U, Bhuiyan I. Improving Adolescent's Reproductive Health. Bangladesh. Research Update, Number 1. Dhaka: Population Council, 2001.

23. Abrar N, Ghouri AM. AIDS/HIV knowledge, attitude and beliefs of adolescents of Pakistan. Eur J Soc Sciences 2010;16:267-77.
24. Jashimuddin M, Choudhury AM. Reproductive health awareness among adolescent girls in rural Bangladesh. Asia Pac J Public Health 2008;20:117-28.

25. Sadhak KC. Base line survey of adolescent's reproductive health interventions in Bangladesh. Dhaka: Bangladesh Center for Communication Programs (BCCP), 2003.

26. Shahid A, Nasim S, Memon AA, Mustafa MA. Adolescent's perspective on reproductive health: A study from Karachi. Pak J Med Res 2012;51:46-51.

27. Butt S, Jejeebhoy S, Shah I, Puri C. Towards adulthood: exploring the sexual and reproductive health of adolescents in South Asia. Geneva: World Health Organization, 2003.

28. UNESCO. Sexuality education in Asia and the Pacific: review of policies and strategies to implement and scale up. Bangkok: UNESCO Office Bangkok and Regional Bureau for Education in Asia and the Pacific, 2012

29. WHO. Making health services adolescent friendly: Developing national quality standards for adolescentfriendly health services. Geneva: World Health Organization, 2012. 